\title{
FLUXOS DE INFORMAÇÃO NA PERSPECTIVA ORGANIZACIONAL
}

\section{FLUJO DE INFORMACIÓN SOBRE PERSPECTIVA ORGANIZACIONAL}

\begin{abstract}
Danielly Oliveira Inomata - inomata.danielly@gmail.com Doutoranda em Ciência da Informação pela Universidade Federal de Santa Catarina (UFSC).

Wánderson Cássio Oliveira Araújo - wcassio@unir.br Mestre em Ciência da Informação, pela Universidade Federal de Santa Catarina (UFSC). Professor do Departamento de Ciência da Informação da Universidade Federal de Rondônia (UNIR).

Gregório Varvakis - grego@egc.ufsc.br Doutor em Manufacturing Engineering pela Loughborough University of Technology (1991). Professor do Departamento de Engenharia do Conhecimento da Universidade Federal de Santa Catarina (UFSC).
\end{abstract}

\footnotetext{
RESUMO

Introdução: Os fluxos de informação são os princípios vitais que suportam os processos, a tomada de decisão e o desenvolvimento de produtos na organização.

Objetivo: Apresentar e descrever os modelos de fluxos de informação encontrados na literatura e difundidos na Ciência da Informação, destacando as etapas, os contextos e os principais resultados identificados.

Metodologia: Busca exploratória, seguindo os seguintes critérios para a seleção dos modelos: a) apresentação de um modelo esquematizado; b) descrição das etapas que compõe o fluxo.

Resultados: São detalhados oito modelos, os quais reproduzem com eficiência 0 processo de gestão da informação baseada nos fluxos informacionais. Os modelos apresentam características similares, mas possuem um viés especifico, seja aplicada a comunicação, à administração da informação ou um viés mais cognitivo. Identificaram-se elementos e aspectos que influenciam o fluxo da informação.

Conclusões: No contexto organizacional a agregação de valor à informação, que percorre o fluxo, deve estar alinhada aos objetivos da organização. 0 estudo do fluxo permite caracterizar um processo enxuto e simples, a partir da identificação de seus elementos, considerando também o elemento homem como artefato para ter conhecimento e integrar este processo.
} 
Danielly Oliveira Inomata; Wánderson Cássio Oliveira Araújo; Gregório Varvakis

Fluxos de informação na perspectiva organizacional

Palavras-chave: Fluxos de informação. Modelos de fluxos de informação. Gestão da informação. Valor agregado.

\section{INTRODUÇÃO}

Em todas as atividades da organização a informação é um fator crítico (DAVENPORT; PRUSSAK, 2004). Este trabalho não busca definir informação, mas sim é um exercício de reflexão ${ }^{1}$ sobre como os fluxos de informação são representados nas organizações que demandam respostas imediatas para ação, isso significa que a informação deve ter valor agregado.

O valor agregado está pautado no processo de uso da informação, o qual é situacional, ou seja, é inerente a cada organização, ambiente e colaboradores. Por esta razão, o julgamento dos processos de custo e benefício das informações e a análise de informações se tornam mais dinâmicos. (MIRANDA, 2006).

Tal reflexão acerca dos fluxos se apresenta como uma necessidade contemporânea a ser amplamente discutida, haja vista que, de forma geral, a sociedade é composta por diferentes fluxos, podendo ser citados: os fluxos de capital, fluxos de informação, fluxos de tecnologia, fluxos de interação organizacional, fluxos de imagens, sons e símbolos (CASTELLS, 2005). No contexto organizacional, Porter (2009) esclarece que a tecnologia da informação modificou a forma como a informação é utilizada nas organizações, assim, modificando o contexto da gestão da informação.

Pesquisar os fluxos de informação no contexto organizacional é um movimento natural de estudo na Ciência da Informação $(\mathrm{Cl})$, considerando que as organizações são construídas com base nas informações que possuem $(\mathrm{CHOO}, 2006)$ e, consequentemente, os

\footnotetext{
1 Ação de introspecção que investiga e examina a natureza da atividade e estabelece os princípios que a fundamentam. (JAPIASSÚ; MARCONDES, 2001).
} 
Danielly Oliveira Inomata; Wánderson Cássio Oliveira Araújo; Gregório Varvakis

Fluxos de informação na perspectiva organizacional

fluxos de informação são os princípios vitais que suportam os processos, as tomadas de decisão, o desenvolvimento de produtos etc. (DURUGBO; TIWARI; ALCOCK, 2013).

O objetivo deste trabalho é apresentar e descrever alguns modelos de fluxos de informação encontrados na literatura e difundidos na $\mathrm{Cl}$, destacando as etapas, os contextos e os principais resultados identificados.

Nas seções seguintes são apresentadas a metodologia adotada; uma breve apresentação dos fluxos de informação, especialmente a caracterização do modelo, contrapondo aos processos de gestão da informação, para na sequência descrever os modelos identificados. $\mathrm{Na}$ seção quatro são tecidas discussões sobre os modelos caracterizados, e por fim as conclusões e referências.

\section{METODOLOGIA}

Esta pesquisa é de caráter exploratório, por considerar que o tema escolhido é bastante genérico, procurando o esclarecimento e a delimitação (GIL, 2010). A busca exploratória inicialmente ocorreu pela identificação de artigos que apresentassem modelos de fluxos de informação na BRAPCI (Base de Dados Referencial de Artigos de Periódicos em Ciência da Informação), complementada de buscas direcionadas ao tema em livros da Ciência da informação e áreas afins. Ao todo foram identificados 8 modelos de fluxos de informação.

Destaca-se que para este trabalho foi considerado prioritário conhecer os fluxos de informação por meio dos modelos descritos na literatura, visando evidenciar os elementos que o compõem e os aspectos que afetam este processo, visando o entendimento dessas variáveis atuantes no fluxo informacional. Sendo assim, para dar seguimento ao objetivo do trabalho, fez-se uma busca exploratória direcionada ao tema. 
Danielly Oliveira Inomata; Wánderson Cássio Oliveira Araújo; Gregório Varvakis

Fluxos de informação na perspectiva organizacional

Marchionini (2006) classifica as atividades de busca exploratória em dois tipos principais: 1) Aprendizagem: atividades que envolvem o processamento cognitivo e a interpretação de conhecimento novo; e, 2) Investigação: atividades que requerem avaliação crítica antes da integração nas bases de conhecimento.

Como procedimento para cumprir essas etapas, os critérios escolhidos para seleção de um documento bibliográfico para análise e posterior descrição foi que: a) apresentasse um modelo esquematizado; e, b) descrevesse as etapas que compõe o fluxo. Com isso seria possível contemplar aqueles modelos que de fato se aproximavam da realidade organizacional.

\section{MODELOS DE FLUXOS DE INFORMAÇÃO}

A organização é uma 'entidade de comunicação', composta por pessoas que podem ter acesso a informações e que se comunicam umas com as outras (CLEGG; KORNBERGER; PITSIS, 2011; DURUGBO; TIWARI; ALCOCK, 2013). Diante dessas caracteristicas, modelar o fluxo de informação para as organizações é um desafio, ao considerar que "dentro de uma organização, a comunicação para o fluxo de informações pode envolver diferentes grupos, processos, pessoas, canais de comunicação e assim por diante" (DURUGBO; TIWARI; ALCOCK, 2013, p. 598).

Vários estudos (BARRETO, 2002; BEAL, 2007; CHOO, 2006; FORZA; SALVADOR, 2001; LEITÃO, 1985; LESCA; ALMEIDA, 1994; NAVARRO, 2000) apontados na literatura revelam modelos diferenciados de fluxos de informação, isso está relacionado ao contexto organizacional, ambiental e informacional, particular de cada segmento.

É importante evidenciar que um 'modelo' é a idealização de uma realidade, logo é limitado, por isso não é adaptado integralmente a nenhuma organização, mas é possível identificar um modelo ou combinar modelos a partir de peculiaridades entre organizações, servindo como parâmetros de análise. 
Danielly Oliveira Inomata; Wánderson Cássio Oliveira Araújo; Gregório Varvakis

Fluxos de informação na perspectiva organizacional

Foram escolhidos oito modelos para representar o processo da informação na organização, ao mesmo tempo com a intenção de compreender esses fluxos, seguidamente representados.

\subsection{Modelo de Leitão (1985)}

O modelo de Leitão (1985) apresenta-se como resultado do estudo relacionado à informação como insumo e produto do desenvolvimento tecnológico de um país ou de uma empresa, visto que esse desenvolvimento tecnológico tem sua base no aprendizado tecnológico que ocorre nas pessoas. Por isso, o autor, em sua pesquisa, tratou o objeto de estudo sob a ótica do nível individual e do nível da empresa.

O nível individual permite analisar o fluxo da informação que ocorre entre os indivíduos e como eles se interligam com o processo de aprendizagem. O nível da empresa permite avaliar os novos atores, esta avaliação é considerada importante, pois, converge para a melhor compreensão do relacionamento entre informação e desenvolvimento tecnológico. Na Figura 1, apresenta-se o modelo de Leitão, no nível de empresa.

Figura 1 - Fluxo de informação em nível de empresa

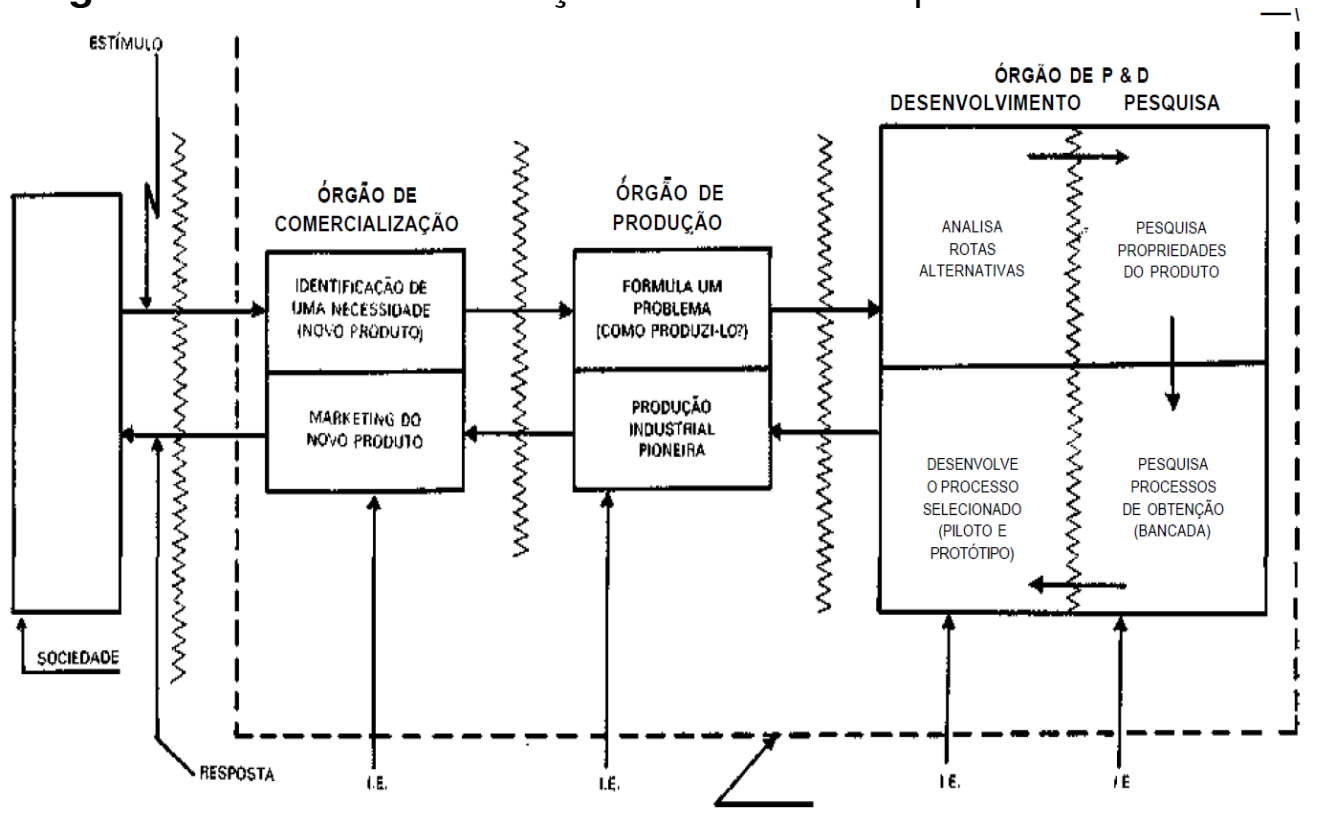

Fonte: Leitão (1985). 
Danielly Oliveira Inomata; Wánderson Cássio Oliveira Araújo; Gregório Varvakis

Fluxos de informação na perspectiva organizacional

Na compreensão de Leitão (1985), a informação nesse contexto era tida como um processo de aprendizado, ficando evidente a interrelação entre ambas. O estudo de Leitão (1985) concluiu que na prática a falta de compreensão de como acontece o fluxo da informação e das dificuldades envolvidas na utilização das informações ocorrem por causa de barreiras informacionais. Na época o autor relacionou ao fato de muito ter-se escrito e falado sobre explosão da informação e pouco terse lido e escutado sobre tal.

Em resumo esse modelo se propõe analisar o fluxo informacional em: a) nível de indivíduo, simplificado, num processo que possui três elementos principais: um emissor, uma mensagem (a informação) e um receptor (indivíduo submetido ao aprendizado tecnológico). Como outros elementos, identificou: barreiras (internas e externas) e ruídos, os códigos (qualquer grupo de símbolos estruturado de forma a ter significado) e, os canais através dos quais as informações são transmitidas; b) nível de empresa, simplificadamente, representada por três de suas funções: pesquisa e desenvolvimento (P\&D), produção e comercialização.

\subsection{Modelo de Lesca e Almeida (1994)}

Lesca e Almeida (1994, p. 7) versam sobre a visão global da informação da empresa a servir de base para uma administração da qualidade dos fluxos de informação (Figura 2).

Os autores propõem a divisão da informação da empresa em três grandes fluxos: Fluxo de informação produzida pela empresa para uso interno - etapa do fluxo produzido e destinado à organização, ou seja, o fluxo no âmbito interno de informações; Fluxo de informação captada fora da empresa e utilizada pela empresa - etapa do fluxo da informação advindo do ambiente externo e utilizado pela organização; Fluxo de informação produzida pela empresa orientada para fora da empresa - etapa produzida pela organização e destinada ao mercado externo da organização (clientes, fornecedores e concorrentes). 
Danielly Oliveira Inomata; Wánderson Cássio Oliveira Araújo; Gregório Varvakis

Fluxos de informação na perspectiva organizacional

Figura 2 - Os três fluxos de informação da empresa

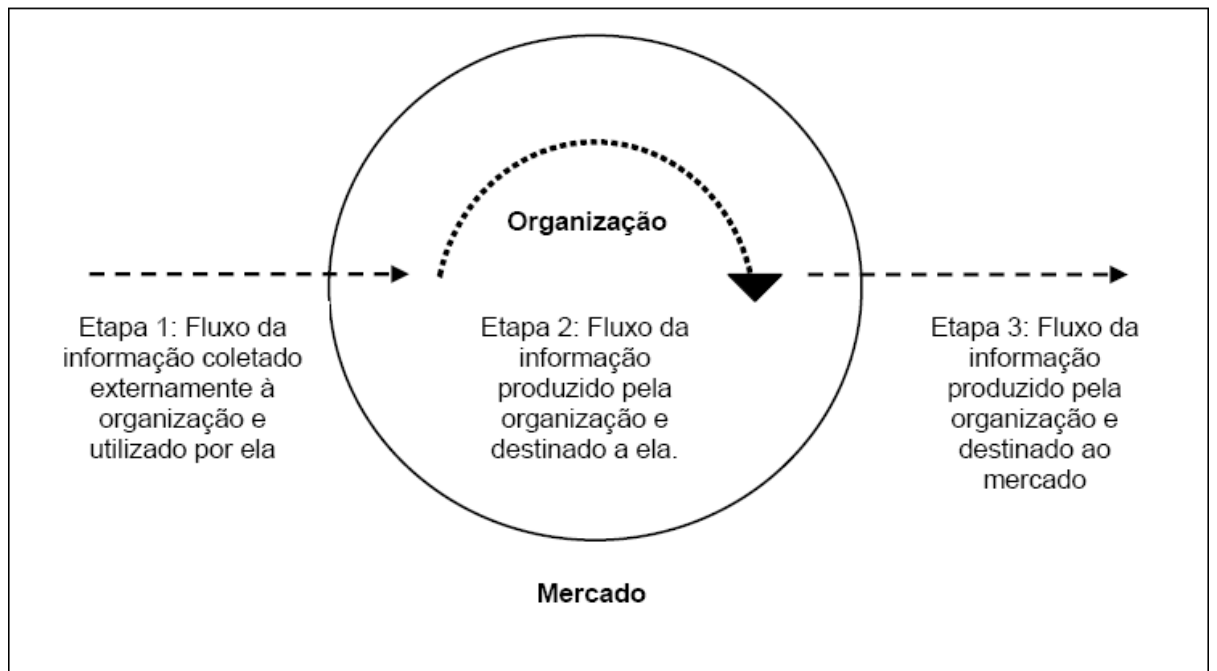

Fonte: Lesca e Almeida (1994).

Neste modelo, cada um dos fluxos apresenta dois componentes: informação de atividade - aquela que permite à empresa garantir seu funcionamento; e, informação de convívio - aquela que permite que os indivíduos convivam em relação uns com os outros, permitindo também influenciar seus comportamentos.

Lesca e Almeida (1994) concluem que a informação é um recurso que pode ser administrado para se obter vantagem competitiva, e que a informação de atividade é indispensável ao funcionamento da empresa, e a informação de convívio é indispensável para a existência da empresa.

Em suma, as abordagens apresentadas pelos autores, no modelo para a administração dos fluxos de informação da empresa, são orientadas tanto para empresas que ainda não iniciaram o processo de sensibilização de que a administração com qualidade dos fluxos informacionais auxilia a administração estratégica para a vantagem competitiva, como para aquelas empresas que já possuem estratégias avançadas de gestão da informação. 
Danielly Oliveira Inomata; Wánderson Cássio Oliveira Araújo; Gregório Varvakis

Fluxos de informação na perspectiva organizacional

\subsection{Modelo Davenport e Prusak (1998)}

O modelo de Davenport e Prusak representa a cooperação entre os atores envolvidos no fluxo de informação, o qual é a chave para que a informação possa circular na organização, chamados pelos autores de processo genérico de gerenciamento da informação. Esse processo é dividido em quatro etapas, como apresentado na Figura 3.

Figura 3 - Fluxo de Informação: modelo Davenport

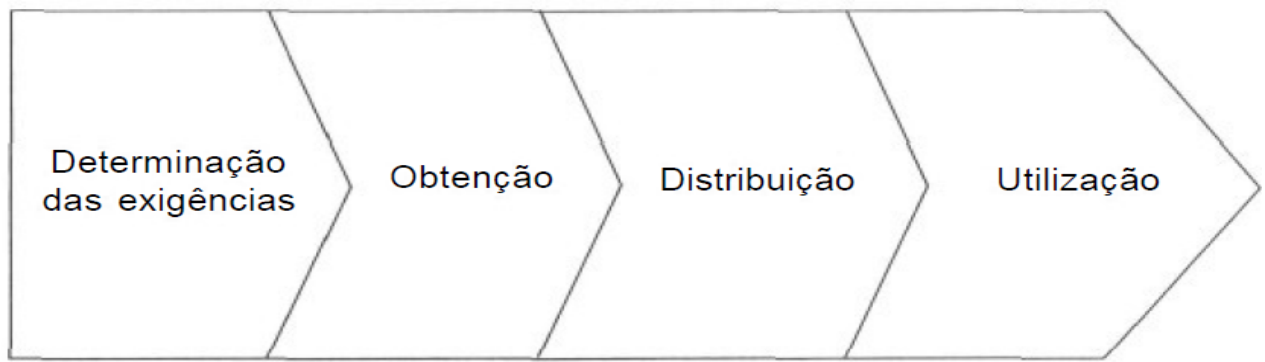

Fonte: Davenport e Prusak (2004)

O modelo é composto por quatro fases distintas que possuem um caráter linear:

1) Determinação das exigências: define quais informações são necessárias e para qual finalidade. Essa etapa é resultado da identificação do problema informacional que a organização possui e que necessita ser solucionado;

2) Obtenção: define as estratégias de busca da informação e a implantação dessa obtenção, essa etapa deve estar alinhada com a etapa anterior. É necessário considerar amplas possibilidades de fontes de informação e deve ser um processo contínuo na organização;

3) Distribuição: se refere à informação obtida começa a circular na organização a fim de suprir as necessidades informações de indivíduos. Essa etapa deve sempre levar em consideração os problemas informacionais existentes na organização para que essa distribuição seja eficaz;

4) Utilização: define o uso da informação se apresenta como um processo cognitivo que abrangem a recepção da informação pelo indivíduo, sua internalização e a sua transformação em conhecimento para resolver seus problemas informacionais.

As pessoas são consideradas pessoas chave no fluxo de informação, ou seja, o fator humano é o real responsável pela circulação 
Danielly Oliveira Inomata; Wánderson Cássio Oliveira Araújo; Gregório Varvakis

Fluxos de informação na perspectiva organizacional

do conhecimento na organização. As TIC funcionam como suporte ao processo informacional. (DAVENPORT; PRUSAK, 2004).

\subsection{Modelo de Navarro (2000)}

O modelo de Navarro descreve a relação entre fluxos e canais de informação nas organizações. A autora aponta fluxos como caminhos, as direções físicas que a informação toma dentro de uma organização, geralmente são caminhos de ida e volta, onde ocorre o feedback de informações, normalmente os dados são alcançados ou retornados, fornecendo informações mais significativas.

$\mathrm{Na}$ visão de Navarro (2000) são nesses caminhos que os conteúdos são enriquecidos dentro da organização. Neste modelo, a ideia central está baseada na existência de canais formais e informais, sendo estes os geradores de fluxos formais e informais.

Navarro pondera que as informações veiculadas por estes canais são igualmente válidas, no entanto, a diferença é que informações geradas através de canais formais podem ser controladas (arquivar, recuperar) enquanto que as informações geradas através de canais informais são muito mais difíceis de armazenar e recuperar.

Figura 4 - Fluxo de Informação em uma Organização

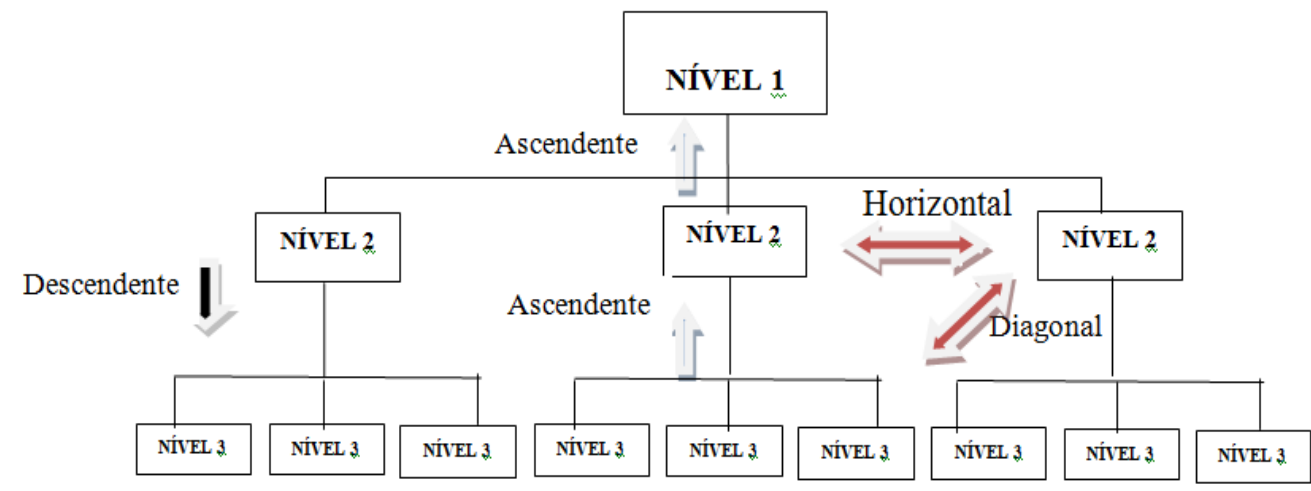

Fonte: Navarro (2000).

Conforme mostra a Figura 3, o modelo permite direcionar três tipos de comunicação: Comunicação ascendente: descrita como comunicação para cima, passa de nível inferior a superior, sobre os 
Danielly Oliveira Inomata; Wánderson Cássio Oliveira Araújo; Gregório Varvakis

Fluxos de informação na perspectiva organizacional

níveis hierárquicos. Este fluxo apresenta obstáculos pelos níveis intermediários; Comunicação descendente: descrita como comunicação de queda, flui dos níveis superiores e níveis hierárquicos. São predominantes na alta direção.

É ressaltado que tanto a globalização dos mercados e a competitividade da empresa são indicadores para a maior atenção aos canais de comunicação, conceituando a comunicação como um processo membro da organização, onde transmitem informação e interpretam seus significados (NAVARRO, 2000).

\subsection{Modelo de Forza e Salvador (2001)}

Neste modelo, os autores Forza e Salvador discutem a influência do fluxo informacional na melhoria da performance das indústrias manufatureiras. O fluxo de informação é entendido como um processo de comunicação promovendo o intercâmbio de informação, para que isso ocorra utiliza como critério a direção que a informação (fluxo) toma dentro de uma organização. Nesta perspectiva, Forza e Salvador (2001) propõem três direções para a comunicação, acontecendo no: Fluxo vertical da informação - a comunicação que ocorrem ao longo das cadeias de comando, tanto ascendente como descendente; Fluxo horizontal de informação - a comunicação que não passam através da cadeia de comando dentro da empresa, isto é, especificamente oriundo das informações que cruzam as linhas hierárquicas da organização; Fluxo externo de informação - a comunicação que liga a empresa com atores (principalmente fornecedores e clientes) através de canais externos à organização. 
Danielly Oliveira Inomata; Wánderson Cássio Oliveira Araújo; Gregório Varvakis

Fluxos de informação na perspectiva organizacional

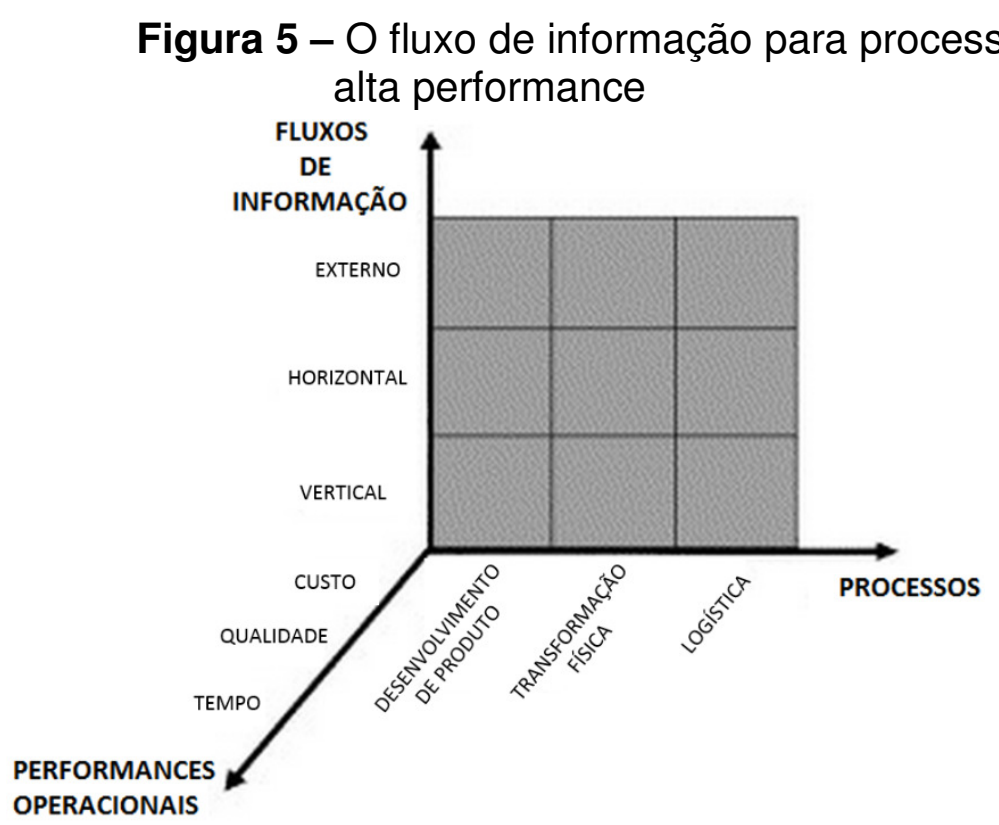

Fonte: Forza e Salvador (2001).

Evidencia-se que tanto no fluxo horizontal quanto vertical, as informações fluem quando aumenta a incerteza da tarefa. Dos resultados obtidos com a investigação de Forza e Salvador (2001), pesquisas empíricas mostram que diferentes fluxos de informação podem ser identificados em uma única organização, porém de difícil avaliar cada um dos fluxos de informação (externo, horizontal e vertical), portanto é necessário encontrar uma maneira de agrupá-los.

É salientado pelos autores que o fluxo horizontal de informação tende a se tornar mais importante, pois a comunicação horizontal oferece o caminho mais curto para se conectar a pessoa a quem pertence e quem precisa de informações operacionais. Além disso, nesse processo de comunicação os canais são mais curtos, evitando assim atrasos e erros na troca de informações, possibilitando o compartilhamento simultâneo de conhecimentos detidos por pessoas em diferentes partes da organização, desencadeando um grande potencial de melhoria.

O fluxo vertical de informação tende a mudar os objetivos e conteúdo, uma vez que delega atividades a níveis hierárquicos mais baixos, no entanto esse tipo de comunicação apoia a resolução de 
Danielly Oliveira Inomata; Wánderson Cássio Oliveira Araújo; Gregório Varvakis

Fluxos de informação na perspectiva organizacional

problemas. Com relação ao fluxo externo de informação, tende a desempenhar um papel cada vez mais importante nas organizações por alinhar as necessidades do cliente, permitindo uma comunicação entre os fornecedores, clientes e a organização.

\subsection{Modelo de Barreto (2002)}

Barreto (2002) propõe uma representação para os fluxos internos e extremos (Figura 4), elaborado com base nas teorias da $\mathrm{Cl}$. O autor explica que a $\mathrm{Cl}$ introduz um pensamento mais direcionado aos fluxos externos - localizados nas extremidades do fluxo interno, enquanto que a Biblioteconomia objetiva o fluxo interno e o seu sistema - abrange seleção, aquisição, catalogação, classificação, indexação, armazenamento, recuperação e disponibilidade para o uso de itens de informação.

Em uma das extremidades há a criação da informação, na outra a assimilação da mesma pelo receptor. Os estoques (ou espaços) de informação e os seus usuários permeiam dois critérios: o critério da tecnologia da informação e o critério da $\mathrm{Cl}$. O primeiro almeja possibilitar o melhor e maior acesso à informação disponível. O segundo intervém para, também, qualificar este acesso em termos de competências para assimilação da informação (BARRETO, 2002).

Nesta perspectiva o fluxo de informação é um processo que se move em dois níveis: o fluxo interno - movimentam entre os elementos de um sistema, orientando-se para uma organização e controle; no segundo nível ocorrem nas extremidades do fluxo interno (de seleção, armazenamento e recuperação da informação); e os fluxos extremos cuja atuação mostra a ação vigorosa do fenômeno de transformação, entre a linguagem do pensamento de um emissor, ou seja, é a linguagem de inscrição do autor da informação e o conhecimento elaborado pelo receptor em sua realidade (BARRETO, 2002). 
Danielly Oliveira Inomata; Wánderson Cássio Oliveira Araújo; Gregório Varvakis

Fluxos de informação na perspectiva organizacional

Figura 6 - Fluxo interno e os fluxos extremos de informação

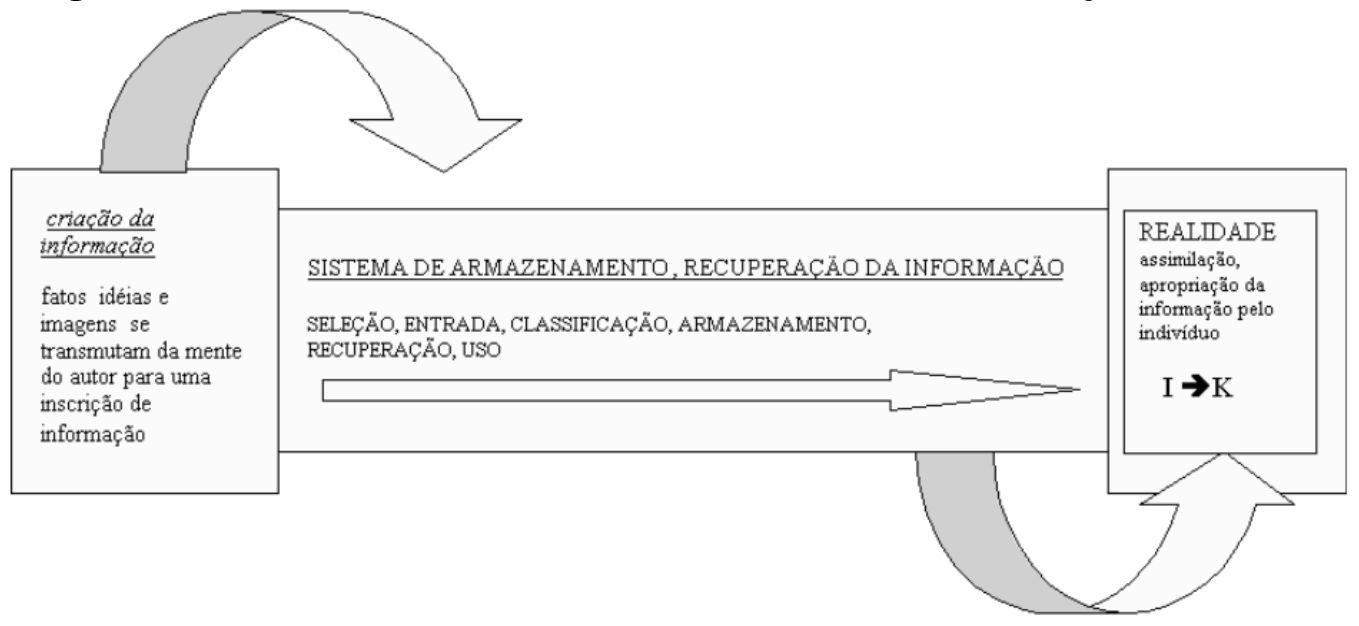

Fonte: Barreto (2002, p. 21).

Ainda, o fluxo opera em um sistema de criação da informação (fatos, ideias e imagens se transmutam da mente do autor para a inscrição de informação), do processamento (seleção, entrada, classificação, armazenamento, recuperação e uso), e posterior consolidação dessa informação como realidade em um processo de transformação da informação (I) em conhecimento $(\mathrm{K})$ pelo indivíduo a partir da assimilação, apropriação da informação.

\subsection{Modelo De Choo (2006)}

Este modelo atende o ciclo de conhecimento, no qual um fluxo contínuo de informações é mantido entre a criação de significado, a construção de conhecimento e a tomada de decisões, de maneira que o resultado do uso de informação em uma etapa ofereça um elaborado contexto, bem como mais recursos para o uso da informação nas outras etapas. 
Danielly Oliveira Inomata; Wánderson Cássio Oliveira Araújo; Gregório Varvakis

Fluxos de informação na perspectiva organizacional

Figura 7 - Modelo processual de administração da informação

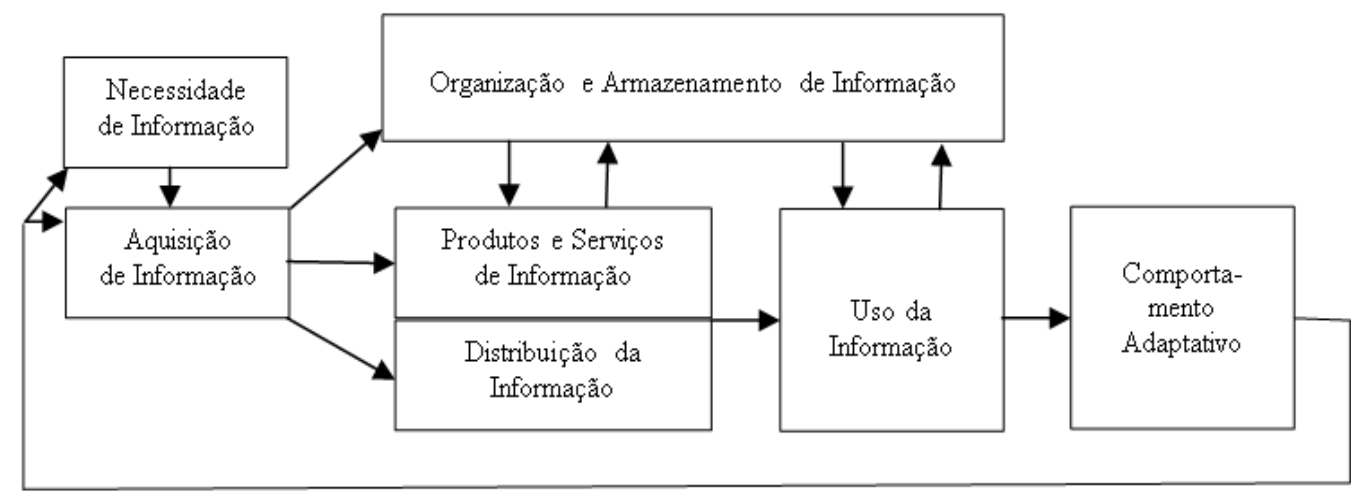

Fonte: Choo (2006).

O conhecimento organizacional pode ser também um modelo processual de administração da informação para isso é necessária ser vista como a gestão de uma rede de processos (adquirir, criar, organizar, distribuir e usar a informação), no entanto, é útil elaborar os processos que compreendem essas amplas categorias com a intenção de criar estratégias de administração da informação, por meio de um ciclo contínuo de seis processos correlatos: 1) Identificação das necessidades de informação; 2) Aquisição da informação; 3) Organização e armazenamento da informação; 4) Desenvolvimento de produtos e serviços de informação; 5) Distribuição da informação; 6) Uso da informação.

O modelo representa uma estrutura para os processos de administração da informação, como um fluxo contínuo para manter e alimentar o conhecimento organizacional, obtido após um comportamento adaptativo - entendido como o uso eficiente da informação -, ressaltando que são ações dirigidas para objetivos, mas que também reagem a condições do ambiente. Nesse modelo, há a interação das reações da organização com as ações de outras organizações, gerando novos sinais e mensagens aos quais se devem atentar, pois isso mantém novos ciclos de uso da informação. (CHOO, 2006). 
Danielly Oliveira Inomata; Wánderson Cássio Oliveira Araújo; Gregório Varvakis

Fluxos de informação na perspectiva organizacional

\subsection{Modelo De Beal (2007)}

Este modelo descreve as atividades relacionadas às etapas dos fluxos da informação nas organizações (Figura 6), que percorre 7 (sete) etapas, como apresentado na Figura 8:

Figura 8 - Modelo proposta para representar o fluxo da informação nas organizações

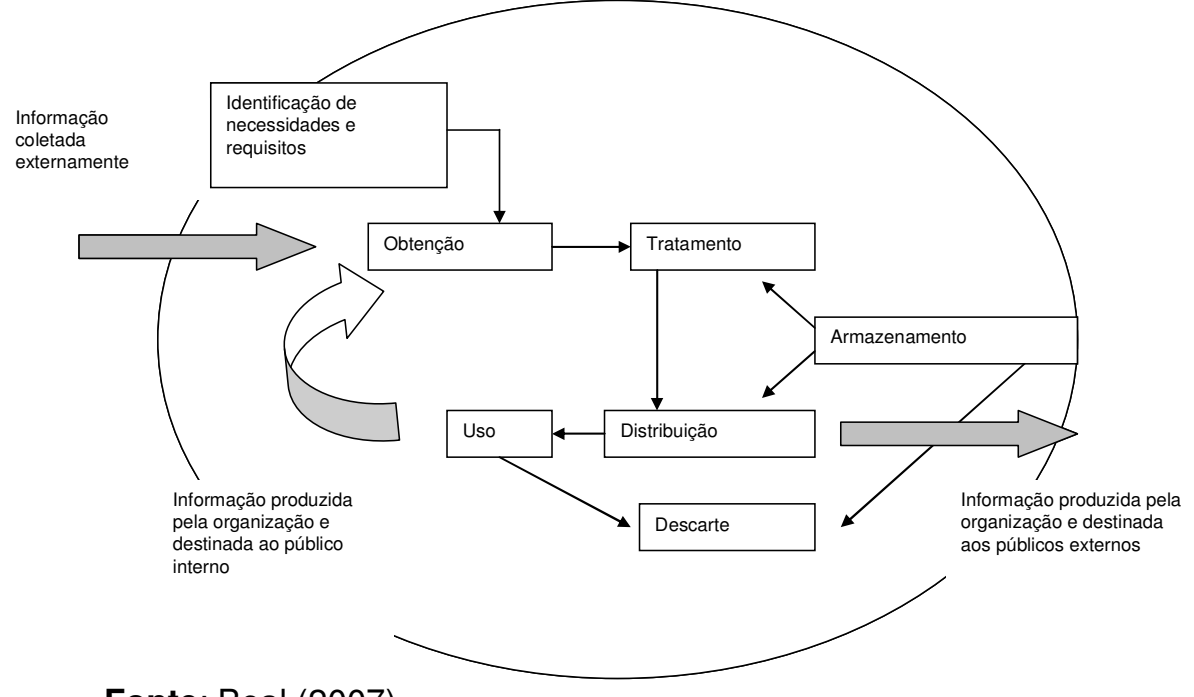

Fonte: Beal (2007).

Primeira etapa (Identificação de necessidades e requisitos): consiste na identificação das necessidades (do grupo ou do indivíduo) e requisitos de informação, o qual ao serem atendidos é recompensado, assim:

[...] quando a informação se torna útil, e seus destinatários mais receptivos a aplicá-la na melhoria de produtos e processos (usuários internos) ou no fortalecimentos dos vínculos e relacionamento com a organização (usuários externos). (BEAL, 2007, p. 30).

$\mathrm{Na}$ segunda etapa (Obtenção): são desenvolvidas as atividades de criação, recepção ou captura de informação, provenientes de fonte interna ou externa em qualquer mídia ou formato.

$\mathrm{Na}$ terceira etapa (Tratamento): é "processo de organização, formatação, estruturação, classificação, análise, síntese e apresentação, 
Danielly Oliveira Inomata; Wánderson Cássio Oliveira Araújo; Gregório Varvakis

Fluxos de informação na perspectiva organizacional

com o propósito de torná-la mais acessível e fácil de localizar pelos usuários" (BEAL, 2007, p. 30).

A etapa seguinte (Distribuição) prevê o direcionamento da informação necessária a quem precisa, neste processo, "quanto melhor a rede de comunicação da organização, mais eficiente é a distribuição interna da informação", além disso, como ressalta a autora, normalmente a organização precisa preocupar-se com os processos de distribuição de informação para públicos externos, referindo-se a distribuição para o mercado, como parceiros, fornecedores, clientes, acionistas, governo etc. (BEAL, 2007, p. 31).

A quinta etapa (Uso) é considerada a mais importante pela autora, a medida que:

[...] o uso da informação possibilita a combinação de informações e o surgimento de novos conhecimentos, que podem voltar a alimentar o ciclo da informação corporativo, num processo contínuo de aprendizado e crescimento. (BEAL, 2007, p. 31).

Na sexta etapa (Armazenamento) "é necessária para assegurar a conversão dos dados e informações permitindo seu uso e reuso dentro da organização". (BEAL, 2007, p. 31).

$\mathrm{Na}$ última etapa (Descarte), o modelo prevê o descarte da informação, obedecendo a normas legais, políticas operacionais e exigências internas ao excluir informações inúteis. Para Beal (2011), a economia de recursos de armazenamento, a velocidade de obtenção da informação e a eficiência na localização da informação necessária são elencadas como as maiores vantagens na melhoria dos processos de gestão da informação.

\section{DISCUSSÕES SOBRE OS MODELOS}

Os modelos apresentados reproduzem com eficiência o processo de gestão da informação baseada nos fluxos informacionais. No entanto, analisando os modelos, nota-se que todos os modelos possuem 
Danielly Oliveira Inomata; Wánderson Cássio Oliveira Araújo; Gregório Varvakis

Fluxos de informação na perspectiva organizacional

características similares e por outro lado apresentam um viés específico, seja para a comunicação da informação, como os modelos de Navarro (2000) e Forza e Salvador (2001), seja como uma representação mais cognitiva da informação, como modelo de Barreto (2002).

Verificou-se que, Davenport e Prussak (2004) apresentam um modelo simples que funciona de forma linear e que não permite adaptabilidade em contexto complexo como são os informacionais. O modelo proposto por Beal (2007) é o mais amplo pelo fato de possuir a etapa de descarte da informação, quando esta se torna inútil. Se comparado, o modelo de Beal (2007) e o modelo de Lesca e Almeida (1994), especialmente em relação aos fluxos provenientes do ambiente externo, o ambiente interno e o destinado ao mercado externo são muito semelhantes.

O modelo de Choo (2006) também é peculiar, pois prevê o comportamento adaptativo, ou seja, presume quais as informações que de fato são eficientes para o uso na organização. Outro aspecto relevante é o fato de entender o fluxo como processual mantido entre as três arenas (criar significado, construir conhecimento e tomar decisões), de modo que a informação deve agregar valor para ser repassada para o próximo modo.

O modelo de Leitão (1985), embora seja o mais antigo, apresenta uma perspectiva para análises em diferentes níveis (individual e empresarial), sinalizando a complexidade dos estudos sobre fluxos de informação em organizações.

A literatura demonstra que a utilização de forma efetiva da informação interna e externa é primordial para a identificação do fluxo da informação, os fatores impactantes deste processo, os tipos de informações existentes e necessárias para a agregação de valor visando o gerenciamento da informação (CALAZANS, 2006). Porém, os fluxos são diferentes quando em contextos e cenários diferenciados. Mas ofertar informação com qualidade é a função do processo que forma 0 fluxo, no entanto é importante deixar em evidência que um processo 
Danielly Oliveira Inomata; Wánderson Cássio Oliveira Araújo; Gregório Varvakis

Fluxos de informação na perspectiva organizacional

(fluxo) claramente definido não é garantia de qualidade do mesmo, porque no processo ocorrem falhas decorrentes de situações não previstas, por exemplo.

Assim sendo, o estudo do fluxo permite caracterizar um processo enxuto e simples, a partir da identificação de seus elementos, considerando também o elemento homem como artefato para ter conhecimento e integrar este processo. Com isso, estabelecer avaliação e melhoria contínua a partir do diagnóstico como forma de prever a eficiência (processo) e a eficácia (resultado) do fluxo informacional.

Os fluxos de informação podem ser fortemente influenciados pelos relacionamentos humanos dentro de uma organização, com isso, certamente os contextos devem ser levados em questão, por serem agentes que interferem na percepção e condução dos processos (VITAL; FLORIANI; VARVAKIS, 2010).

Como destacam Inomata (2012), Inomata e Rados (2015), o fluxo de informação é um processo cuja dinâmica envolve uma sucessão de eventos, envolvendo um ponto de partida, uma mensagem e um destino para a informação num ciclo contínuo, que depende de uma mecânica que envolve um conjunto de elementos (atores, canais, fontes de informação e tecnologias da informação e comunicação) e aspectos influentes ao processo informacional (barreiras, escolha e uso da informação, necessidades informacionais e velocidade).

Com a análise dos modelos foi possível elencar um conjunto de fatores que são componentes intrínsecos à construção e funcionamento dos processos de circulação e criação de valor da informação na organização (Quadro 1). 
Danielly Oliveira Inomata; Wánderson Cássio Oliveira Araújo; Gregório Varvakis

Fluxos de informação na perspectiva organizacional

Quadro 1 - Fatores que compõe o fluxo de informação

\begin{tabular}{|c|c|c|c|}
\hline Dimensões & Categoria & Conceito & Autores \\
\hline \multirow{4}{*}{$\begin{array}{l}\stackrel{0}{O} \\
\stackrel{+}{\Phi} \\
\frac{E}{\Phi} \\
\frac{\Phi}{\Psi}\end{array}$} & Atores & $\begin{array}{l}\text { Todos os envolvidos no } \\
\text { fluxo de informação, e nas } \\
\text { atividades inerentes ao } \\
\text { fluxo, e que, de alguma } \\
\text { forma, são responsáveis } \\
\text { para que o fluxo ocorra. }\end{array}$ & $\begin{array}{l}\text { Allen (1966); Choo (2006); } \\
\text { Davenport; Prusak (1998); Le } \\
\text { Coadic (2004); Silva; Lopes } \\
\text { (2011); Vaz (2004) }\end{array}$ \\
\hline & Canais & $\begin{array}{l}\text { Responsáveis por suporte } \\
\text { à transmissão de de } \\
\text { informações no processo } \\
\text { de comunicação. }\end{array}$ & $\begin{array}{l}\text { Alves; Barbosa (2010); Calva } \\
\text { Gonzalez (2004); Fujino (2007); } \\
\text { Kwasitsu (2003) }\end{array}$ \\
\hline & $\begin{array}{l}\text { Fontes de } \\
\text { informação }\end{array}$ & $\begin{array}{l}\text { Insumo para a obtenção } \\
\text { dos mais variados tipos de } \\
\text { informação que darão } \\
\text { suporte para as atividades } \\
\text { que o fluxo de informação } \\
\text { está inserido. }\end{array}$ & 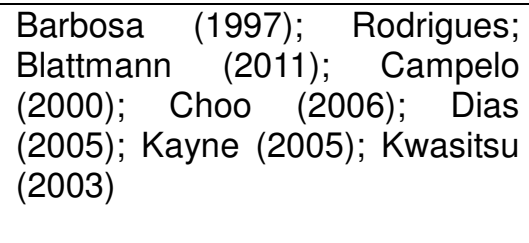 \\
\hline & $\begin{array}{c}\text { Tecnologias } \\
\text { da } \\
\text { informação } \\
e \\
\text { comunicaç } \\
\text { ão }\end{array}$ & $\begin{array}{lcr}\text { Suportes } & \text { para } & \text { que } \\
\text { operações } & \text { do } & \text { fluxo } \\
\text { aconteçam } & \text { de } & \text { forma } \\
\text { exequível. } & & \end{array}$ & $\begin{array}{l}\text { Castells (2005); Davenport; } \\
\text { Prusak (1998); Meyer; Marion } \\
\text { (2013); Molina (2010); Saracevic } \\
\text { (1996); Kwasitsu (2003) }\end{array}$ \\
\hline \multirow{4}{*}{$\begin{array}{l}0 \\
\text { O } \\
\text { d } \\
\frac{0}{2} \\
\frac{1}{4}\end{array}$} & Barreiras & $\begin{array}{l}\text { Entraves ocasionalmente } \\
\text { encontrados no caminho } \\
\text { que a informação deve } \\
\text { percorrer. }\end{array}$ & $\begin{array}{ll}\text { Alves; Barbosa (2010); Sousa; } \\
\text { Amaral (2012); Starec } & (2002) ; \\
\text { Valentim; Texeira } & (2012) ; \\
\text { Kwasitsu (2003) } & \\
\end{array}$ \\
\hline & $\begin{array}{l}\text { Escolha e } \\
\text { uso da } \\
\text { informação }\end{array}$ & $\begin{array}{l}\text { Aspectos que interferem } \\
\text { na escolha da fonte e do } \\
\text { uso da informação. }\end{array}$ & 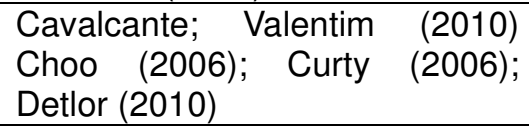 \\
\hline & $\begin{array}{l}\text { Necessidad } \\
\text { es } \\
\text { informacion } \\
\text { ais }\end{array}$ & $\begin{array}{l}\text { Fator responsável pelo } \\
\text { início do processo e do } \\
\text { fluxo de informação. }\end{array}$ & $\begin{array}{l}\text { Bettiol (1990); Calva Gonzalez } \\
\text { (2004); Fadel et. al. (2010); } \\
\text { Martínez-Silveira; } \\
\text { (2007) }\end{array}$ \\
\hline & Velocidade & $\begin{array}{l}\text { Tempo de resposta entre a } \\
\text { necessidade da informação } \\
\text { e a resposta obtida. }\end{array}$ & $\begin{array}{l}\text { Davenport; Prusak (1998); } \\
\text { Detlor (2010); Dewett; Jones, } \\
\text { 2011; Grácio; Fadel (2010) }\end{array}$ \\
\hline
\end{tabular}

Fonte: Desenvolvido pelos autores.

Esses fatores auxiliaram na confirmação de um levantamento bibliográfico realizado em trabalhos anteriores (ARAÚJO, 2014; CURTY, 2005; INOMATA, 2012; PASSOS, 2012), permitindo elencar oito fatores que constituem o fluxo de informação no contexto organizacional, divididos em duas dimensões (elementos que compõe o fluxo e aspectos que o influenciam), os quais são apresentados no Quadro 1. A composição desses fatores se apresenta como complementares e mutuamente dependentes sugerindo um processo complexo que 
Danielly Oliveira Inomata; Wánderson Cássio Oliveira Araújo; Gregório Varvakis

Fluxos de informação na perspectiva organizacional

possibilita a criação de valor por meio do processo informacional. Esses fatores podem ser analisados em um contexto individual e em um contexto sistêmico, possibilitando um entendimento maior do fluxo de informação em uma organização.

Entende-se que tais fatores são categorias de análise para promover o aprofundamento das questões referentes ao fluxo de informação no contexto organizacional. Compreendendo que a partir do conhecimento desses fatores, seja possível entender o papel dos atores do fluxo, aprimorar e/ou propor novos canais de comunicação, atualizar e expandir as opções de fontes de informação, melhorar o uso das TIC, mitigar e/ou eliminar barreiras, entender o processo de escolha e uso da informação, prever e administrar as necessidades informacionais e, por fim, maximizar a velocidade de resposta informacional, e por consequência aperfeiçoar os processos, as etapas e as tarefas que compõe o fluxo de informação.

É válido ressaltar que a análise do fluxo informacional, como parte de um processo auxiliar ao da gestão da informação em uma organização deve ser visto como uma visão parcial da organização, para se chegar a um quadro geral tem que considerar as hierarquias, os processos e as funções organizacionais.

\section{CONCLUSÕES}

O presente trabalho buscou apresentar os fluxos de informações encontrados na literatura de $\mathrm{Cl}$ e que possibilitam o entendimento dos processos informacionais no contexto organizacional. Junto a apresentação dos modelos buscou-se analisá-los de forma comparativa e evidenciar os fatores comuns que compõe esse processo de comunicação.

Os fatores apresentados no Quadro 1, e confirmados com o detalhamento de cada modelo, se sustentam ao considerar a sua aplicação em quatro pesquisas de mestrado (ARAÚJO, 2014; CURTY, 
Danielly Oliveira Inomata; Wánderson Cássio Oliveira Araújo; Gregório Varvakis

Fluxos de informação na perspectiva organizacional

2005; INOMATA, 2012; PASSOS, 2012), fazendo parte da perspectiva metodológica de análise do fluxo de informação proposta pelos autores.

Considera-se que os fluxos de informação são processos variáveis que dependem de um conjunto de aspectos influenciadores que neles incidem. $E$ que o fluxo de informação no contexto organizacional é um processo que proporciona a criação de valor à informação e possibilita que as atividades da organização possam ocorrer, mediante o uso de informações, de forma a atender as necessidades da organização, ou seja, que os fluxos de informação devem estar alinhados aos objetivos organizacionais, possibilitando a ação.

\section{AGRADECIMENTOS}

Os autores agradecem a Fundação de Amparo à Pesquisa do Estado do Amazonas e a Coordenação de Aperfeiçoamento de Pessoal de Nível Superior pelo apoio para concretização dessa pesquisa.

\section{REFERÊNCIAS}

ALVES, Alessandra; BARBOSA, Ricardo Rodrigues. Influências e barreiras ao compartilhamento da informação: uma perspectiva teórica. Ciência da Informação, Brasília, v. 39, n. 2, p. 115-128, maio/ago. 2010.

ARAÚJO, Wánderson Cássio Oliveira. O fluxo de informação em projetos de inovação: estudo em três organizações. 2014. $144 \mathrm{f}$. Dissertação (Mestrado em Ciência da Informação) - Universidade Federal de Santa Catarina, Florianópolis, 2014.

BARBOSA, Ricardo Rodrigo. Acesso e necessidades de informação de profissionais brasileiros: um estudo exploratório. Perspectivas em Ciência da Informação, Belo Horizonte, v. 2, n. 1, p. 5-35, jan./jun. 1997. 
Danielly Oliveira Inomata; Wánderson Cássio Oliveira Araújo; Gregório Varvakis

Fluxos de informação na perspectiva organizacional

BARRETO, Aldo de Albuquerque. O tempo e o espaço da ciência da informação. Transinformação, Campinas, v. 14, n. 1, p. 17-24, jan./jun. 2002.

BEAL, Adriana. Gestão estratégica da informação: como transformar a informação e a tecnologia da informação em fatores de crescimento e de alto desempenho nas organizações. São Paulo: Atlas, 2007.

BETTIOL, Eugênia Maranhão. Necessidades de informação: uma revisão. Revista de Biblioteconomia de Brasília, Brasília, v. 18, n. 1, p. 59-69, jan./jun. 1990.

CALVA GONZÁLEZ, Juan José. Las necesidades de información: fundamentos teóricos y métodos. México: Universidad Nacional Autónoma de México, 2004.

CAMPELO, Bernardete Santos. Organizações como fonte de informação. In: CAMPELO, Bernardete Santos; CEDÓN, Beatriz Valadares; KREMER, Jeannete Marguerite. Fontes de informação para pesquisadores e profissionais. Belo Horizonte: UFMG, 2000.

CASTELLS, Manuel. O espaço de fluxos. In: rede. 8. ed. São Paulo: Paz e Terra, 2005. p. 467-521.

CAVALCANTE, Luciane de Fátima Beckman; VALENTIM, Marta Lígia Pomim. Informação e conhecimento no contexto de ambientes organizacionais. In: VALENTIM, Marta Lígia Pomim. Gestão, mediação e uso da informação. São Paulo: Cultura Acadêmica, 2010. p. 235-254.

$\mathrm{CHOO}$, Chun Wei. A organização do conhecimento: como as organizações usam a informação para criar significado, construir conhecimento e tomar decisões. 2. ed. São Paulo: SENAC, 2006.

CLEGG, Stewart R.; KORNBERGER, Martin; PITSIS, Tyrone. Managing and organizations: an introduction to theory and practice. Thousand: Sage, 2011.

CURTY, Renata Gonçalves. O fluxo da informação em contextos dinâmicos: reflexos acerca da informação tecnológica no processo de inovação industrial. In: CUNHA, Miriam Vieira; SOUZA, Francisco das Chagas de (Org.). Comunicação, gestão e profissão: abordagens para o estudo da ciência da informação. Belo Horizonte: Autêntica, 2006.

CURTY, Renata Gonçalves. O fluxo da informação tecnológica no projeto de produtos em indústrias de alimentos. 2005. $249 \mathrm{f}$. Dissertação (Mestrado em Ciência da Informação) - Pós-Graduação em Ciência da Informação, Universidade Federal de Santa Catarina, Florianópolis, 2005. 
Danielly Oliveira Inomata; Wánderson Cássio Oliveira Araújo; Gregório Varvakis

Fluxos de informação na perspectiva organizacional

DAVENPORT, Thomas H.; PRUSSAK, Laurence. Conhecimento empresarial: como as organizações gerenciam o seu capital intelectual. 8. ed. Rio de Janeiro: Campus, 2004.

DETLOR, Brian. Information management. International Journal of Information Management, Guildford, v. 30, n. 2, p. 103-108, Apr. 2010.

DIAS, Maria Matilde Kronka. Fontes de informação: um manual para cursos de graduação em biblioteconomia e ciência da informação. São Carlos: EDUFSCAR, 2005.

DURUGBO, Christopher; TIWARI, Ashutosh; ALCOCK, Jeffrey R. Modelling information flow for organisations: a review of approaches and future challenges. International Journal of Information Management, Guildford, v. 33, n. 3, p. 597-610, 2013.

FADEL, Bárbara et al. Gestão, mediação e uso da informação. In: VALENTIM, Marta Lígia Pomim. Gestão, mediação e uso da informação. São Paulo: Cultura Acadêmica, 2010. p. 13-32.

FORZA, Cipriano; SALVADOR, Fabrizio. Information flow for highperformance manufacturing. International Journal of Production Economics, Amsterdam, v. 70, n. 1, p. 21-26, Mar. 2001.

FUJINO, Asa. Gestão de serviços de informação no contexto da cooperação universidade-empresa: reflexões e perspectivas. In: LARA, Marilda Lopes Ginez de; FUJINO, Asa; NORONHA, Daisy Pires. Informação e contemporaneidade: perspectivas. Recife: Nectar, 2007. p. 231-260.

GIL, Antonio Calos. Métodos e técnicas de pesquisa social. 6. ed. São Paulo: Atlas, 2010.

GRÁCIO, José Carlos Abbud; FADEL, Bárbara. Estratégias de preservação digital. In: VALENTIM, Marta Lígia Pomim. Gestão, mediação e uso da informação. São Paulo: Cultura Acadêmica, 2010. p. $59-85$.

INOMATA, Danielly Oliveira. O fluxo da informação tecnológica: uma análise no processo de desenvolvimento de produtos biotecnológicos. 2012. 282 f. Dissertação (Mestrado em Ciência da Informação) Programa de Pós-Graduação em Ciência da Informação, Universidade Federal de Santa Catarina, Florianópolis, 2012.

INOMATA, Danielly Oliveira; RADOS, Gregório Jean Varvakis. A complexidade do fluxo da informação tecnológica e a interação da rede interna no subsídio ao desenvolvimento de produtos biotecnológicos.

Revista de Bibliotecología y Ciencias de la Información, Lima, n. 58, 2015. 
Danielly Oliveira Inomata; Wánderson Cássio Oliveira Araújo; Gregório Varvakis

Fluxos de informação na perspectiva organizacional

JAPIASSÚ, Hilton; MARCONDES, Danilo. Dicionário básico de filosofia. 3. ed. Rio de Janeiro: Jorge Zahar, 2001.

KWASITSU, Lishi. Information-seeking behavior of design, process, and manufacturing engineers. Library \&Information Science Research, Norwood, v. 25, n. 4, p. 459-476, 2003.

LEITÃO, Dorodame Moura. A informação: insumo e produto do desenvolvimento tecnológico. Ciência da Informação, Brasília, v. 14, n. 2, p. 93-107, jul./dez. 1985.

LESCA, Humbert; ALMEIDA, Fernando C. Administração estratégica da informação. Revista de Administração da FEA/USP, São Paulo, v. 29, n. 3, p. 66-75, jul./set. 1994.

MARCHIONINI, Gary. Exploratory search: from finding to understanding. Communications of the ACM, New York, v. 49, n. 4, p. 41-46, 2006.

MARTÍNEZ-SILVEIRA, Martha; ODDONE, Nanci. Necessidades e comportamento informacional: conceituação e modelos. Ciência da Informação, Brasília, v. 36, n. 2, p. 118-127, maio/ago. 2007.

MEYER, Marc H.; MARION, Tucker J. Preserving the integrity of knowledge and information in R\&D. Business Horizons, Bloomington, $v$. 56, n. 1, p. 51-61, Jan./Feb. 2013.

MIRANDA, Silvânia. Como as necessidades de informação podem se relacionar com as competências informacionais. Ciência da Informação, Brasília, v. 35, n. 3, p. 99-114, 2006.

MOLINA, Letícia Gorri. Tecnologias da informação e da comunicação para a gestão da informação e do conhecimento: proposta de uma estrutura tecnológica aplicado aos portais corporativos. In: VALENTIM, Marta. Gestão, mediação e uso da informação. São Paulo: Cultura Acadêmica, 2010. p. 143-168.

NAVARRO, Célia Chaín. Gestión de Inovatión en las organizaciones. Murcia: ICE, 2000.

PASSOS, Ketry Gorete Farias dos. O fluxo de informação no processo de desenvolvimento de jogos eletrônicos. 2012. $223 \mathrm{f}$. Dissertação (Mestrado em Ciência da Informação) - Programa de PósGraduação em Ciência da Informação, Universidade Federal de Santa Catarina, Florianópolis, 2012.

RODRIGUES, Charles; BLATTMANN, Ursula. Uso das fontes de informação para a geração do conhecimento organizacional.

Perspectivas em Gestão \& Conhecimento, João Pessoa, v. 1, n. 2, p. 43-58, jul./dez. 2011. 
Danielly Oliveira Inomata; Wánderson Cássio Oliveira Araújo; Gregório Varvakis

Fluxos de informação na perspectiva organizacional

SARACEVIC, Tefko. Ciência da informação: origem, evolução e relações. Perspectivas em Ciência da Informação, Belo Horizonte, v. 1, n. 1, p. 41-62, jan./jun. 1996.

SILVA, Edna Lúcia da; LOPES, Marili Isensee. A internet, a mediação e a desintermediação da informação. Datagramazero, Rio de Janeiro, v. 2, n. 12, abr. 2011.

SOUSA, Antônio José Figueiredo Peva de; AMARAL, Sueli Angélica do. Impacto do compartilhamento da informação e do conhecimento para o desenvolvimento de inovações em grandes organizações. Perspectivas em Gestão \& Conhecimento, João Pessoa, v. 2, p. 12-26, out. 2012.

STAREC, Claudio. Informação e universidade: os pecados informacionais e barreiras na comunicação da informação para a tomada de decisão na universidade. DataGramaZero, Rio de Janeiro, v. 3, n. 4, ago. 2002.

VALENTIM, Marta Lígia Pomim; TEIXEIRA, Thiciane Mary Carvalho. Fluxos de informação e linguagem em ambientes organizacionais. Informação e Sociedade, João Pessoa, v. 22, n. 2, p.151-156, maio/ago. 2012.

VAZ, Paulo. Mediação e tecnologia. In: MARTINS, Francisco Menezes; SILVA, Juremir Machado da (Org.). A genealogia do virtual: comunicação, cultura e tecnologias do imaginário. Porto Alegre: Sulina, 2004. p. $216-238$.

VITAL, Luciane. P.; FLORIANI, Vivian M.; VARVAKIS, Gregório. Gerenciamento do fluxo de informação como suporte ao processo de tomada de decisão. Informação \& Informação, Londrina, v. 15, n. 1, p. 85-103, jan./jun. 2010.

Title

Flow information on organizational perspective

\section{Abstract}

Introduction: Information flows are vital for the support of processes, decision making and product development in organizations.

Objective: To show and describe models of information flows found in the literature and disseminated in Information Science, highlighting the stages, contexts and key outcomes identified.

Methodology: Exploratory Search, through the following criteria for the selection of the models: a) presentation of a schematic model; b) description of the steps that make up the flow. 
Results: eight models are detailed, which reproduce efficiently the process of information management based on information flows. The models have similar features, but have specific biases, on communication, information management or at the cognitive level. We identified elements and aspects that influence the flow of information.

Conclusions: In the organizational context, information value adding should be aligned with the goals of the organization. The study of flows allows characterizing a lean and simple process, from the identification of its elements, and of humans as artifacts of knowledge and as part of this process.

Keywords: Information flows. Models of information flows. Information management. Value added.

\section{Titulo}

Flujo de información sobre perspectiva organizacional

\section{Resumen}

Introducción: Los flujos de información son principios vitales que soportan los procesos, toma de decisiones y el desarrollo de productos en la organización. Objetivo: Presentar y describir los modelos de flujos de información que se encontraron en la literatura y que fueron difundidos en las Ciencias de la Información, destacando las etapas, contextos y resultados clave identificados.

Metodología: Búsqueda Exploratoria, en base a los siguientes criterios para la selección de los modelos: a) presentación de un modelo esquemático; b) descripción de los pasos que componen el flujo. Resultados: ocho modelos, que reproducen de manera eficiente la gestión de la información en base a los flujos de información. Los modelos tienen características similares, pero tienen sesgos específicos, la comunicación, la gestión de la información o cognitivos. Se identificaron elementos y aspectos que influyen en el flujo de información.

Conclusiones: En el contexto de la organización, la información que agrega valor debe estar alineada con los objetivos de la organización. El estudio del flujo permite caracterizar un proceso simple, desde la identificación de sus elementos, considerando también el elemento "hombre" como artefacto detentor de conocimiento e integrador de este proceso.

Palabras clave: Flujos de información. Modelos de flujos de información. Gestión de la información. Valor agregado.

Recebido em: 09/07/2014

Aceito em: 16/06/2015 